\title{
Transboundary Pollution in the Capital City of Botswana
}

\author{
K. Moloi, T.S. Verma \\ Department of Physics, University of Botswana, P/Bag UB 00704, Gaborone, Botswana, Southern Africa
}

\begin{abstract}
This paper presents aerosol studies carried out in the capital city of Botswana. The use of backward air mass trajectories has shown that elevated concentrations of fine particles correspond to situations when the air mass originated in the Pretoria and Johannesburg region in South Africa. This illustrated transboundary pollution and also served as an example of long distance transport. The results also show a significant contribution of a local generated pollution. The data has been subjected to principal component analysis (PCA) in order to make source apportionment.
\end{abstract}

Keywords-Particulate matter, Correlation, Principal component, Transboundary pollution, Air mass trajectory.

\section{INTRODUCTION}

Some air pollutants are known to circulate globally and deposit on land and water bodies far from their sources. There are generated in one country and felt in others. These require international actions and collaboration to control their formation and effects. Transboundary air pollutants can survive for periods of days or even years and can be transported 100s or thousands of miles before they affect the air we breath, soils, rivers, lakes and/or our food. Transboundary air polutants cause a number of different problems: e.g formation of particles, ground level ozone which are hazardous to health, the formation of acid rain which can damage buildings and sensitive ecosystems and some that are toxic to human health and the environment (http://naei.defra.gov.uk/, 2016). Transboundary air pollution is a particular problem for pollutants that are not easily destroyed or react in the atmosphere to form secondary pollutants. This is why routine monitoring of transboundary atmospheric particles (Clarke et al., 1999) is very important.

An understanding of transboundary pollution is of great importance since a data base on concentration and its fluctuations at different representative sites of a given urban area is of particular relevance to any future planning towards the improvement and control of air quality in countries.
In Botswana air pollution surveillance is carried out by the Department of waste management and pollution control pursuant to the Atmospheric Pollution (Prevention) Act of 1971 (Air Pollution Control, 1995). Most air pollution stations throughout the country are designed to measure sulphur dioxide $\left(\mathrm{SO}_{2}\right)$ and total suspended particulates. Thus, only a few aerosol characteristics have been measured so far.

\section{EXPERIMENT}

Sampling took place in the capital city of Botswana (Gaborone $\left(22.71^{\circ} \mathrm{S}, 25.9^{\circ} \mathrm{E}\right)$ ) with a population of 250000 . The sampling site lies in a residential area located $\approx 500$ meters on the western side from the city centre. The measurement campaign extended from the $10^{\text {th }}$ to $30^{\text {th }}$ of August, 1999. The sampling duration was $12 \mathrm{hrs,} \mathrm{between}$ 8:00 am and 20:00 pm local time.

Aerosol particles were sampled with a dichotomous virtual impactor (Anderson model 245) operating at a total flow rate of $16.7 \mathrm{l} / \mathrm{min}$. In the impactor used in 1999 the cutpoint between coarse and fine particles was $2.5 \mu \mathrm{m}$ and the upper cut-off for coarse particles was $10 \mu \mathrm{m}$, while the lower and upper cut-off for the impactor used in the 1997 measurements were $3.5 \mu \mathrm{m}$ and $18 \mu \mathrm{m}$ respectively. Teflon membrane filters, manufactured by millipore (SA240PR100), were used. These filters have an aerial density of $0.9 \mathrm{mg} \mathrm{cm}^{-2}$, a diameter of $37 \mathrm{~mm}$ and a pore size of $2.0 \mu \mathrm{m}$. The filter material had been evaluated before sampling with regard to its blank values, and was shown to be very clean.

All impactor samples were analysed by multielement energy dispersive X-ray fluorescence (EDXRF) technique. The characteristic radiation from the sample is detected by a $\mathrm{Si}(\mathrm{Li})$ detector (active area $80 \mathrm{~mm}^{2}$, FWHM at $5.9 \mathrm{KeV}$ of $173 \mathrm{eV}$ ). The X-ray tube was operated at a voltage of $55 \mathrm{kV}$ and a current of $25 \mathrm{~mA}$. The live time of each spectrum was 1000 s. For a detailed description of the spectrometer see papers by e.g. Standzenieks and Selin [1979] and Selin et al. [1991]. 
Sulphur dioxide was sampled with a self-contained high sensitivity pulsed fluorescence analyser Model 43S from Thermo Environmental Inc. operating at a flow rate of 0.5 1/min (Thermo Environmental Instruments Inc., 1996). Ten minutes averages were logged in a logger (Campbell CR10). The logger also recorded supporting weather variables like wind speed and direction.

\section{RESULTS AND DISCUSSION}

\subsection{Diurnal variation of elements}

The particulate pollution in Gaborone is a mixture of locally produced and long distance transported aerosol, for which the daily concentration is also dependent on meteorological conditions. This is illustrated by the large diurnal variation shown in Figures 1 and 2. Notice the maximum and minimum values obtained on the $15^{\text {th }}$ August 1999 and $19^{\text {th }}$ August 1999 respectively.

Some indications of whether a source is nearby or far away can be obtained by studies of the relative concentrations of $\mathrm{SO}_{2}$ and fine particulate sulphur, $\mathrm{S}$ (f). For most strong sulphur sources sulphur is emitted in gaseous form, as $\mathrm{SO}_{2}$. In the atmosphere $\mathrm{SO}_{2}$ is, however, oxidised into sulphate at a rate of a few percent per hour [Seinfeld, 1986, Zunkel et al., 1998]. Thus, a good approximation to the situation is to regard $\mathrm{SO}_{2}$ as "young" and $\mathrm{S}$ (f) as "old" sulphur. It is therefore interesting to study the two species of sulphur in the same diagram, as shown in Figures 2 and 3 for the measurement period. From these figures it appears that the ratio between the species is similar for the periods $14^{\text {th }}-16^{\text {th }}$ of August and $25^{\text {th }}-28^{\text {th }}$ of August, while there is higher ratio between $\mathrm{SO}_{2}$ and $\mathrm{S}$ (f) in $17^{\text {th }}-22^{\text {nd }}$ of August, indicating that the nearby source has a relatively greater impact during this period. For the period $17^{\text {th }}-22^{\text {nd }}$ of August, the local wind direction was blowing from the direction of the Gaborone city centre and hence this nearby source is likely to be the Gaborone city centre which has many emission sources. The periods $14^{\text {th }}-16^{\text {th }}$ of August and $25^{\text {th }}-28^{\text {th }}$ of August therefore indicate a larger proportion of long distance, transboundary pollutants. A study of the regression diagram of $\mathrm{SO}_{2}$ and $\mathrm{S}$ (f) for the entire period (Fig. 6) shows an almost linear relation between the two, except for the period with unusually high ratio between $\mathrm{SO}_{2}$ and $\mathrm{S}$ (f), mentioned before and one outlier value with a very high level of $S$ (f) (on the $12^{\text {th }}$ of August). The slope of the regression line in Fig. 6 refers thus to the relative amount of gaseous and fine particle sulphur in the case of long distance transport.

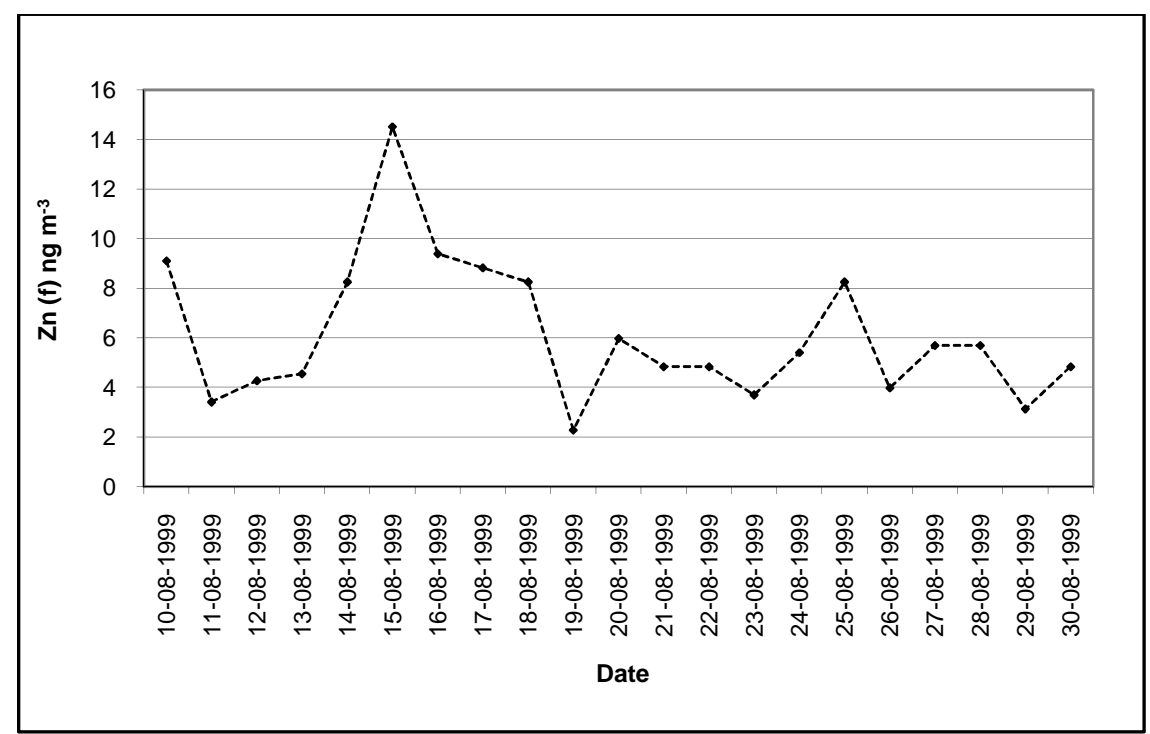

Fig.1: Time series of $\mathrm{Zn}(f)$. Zn is mostly found in the fine particle mode and hence it's most probably anthropogenically generated. 


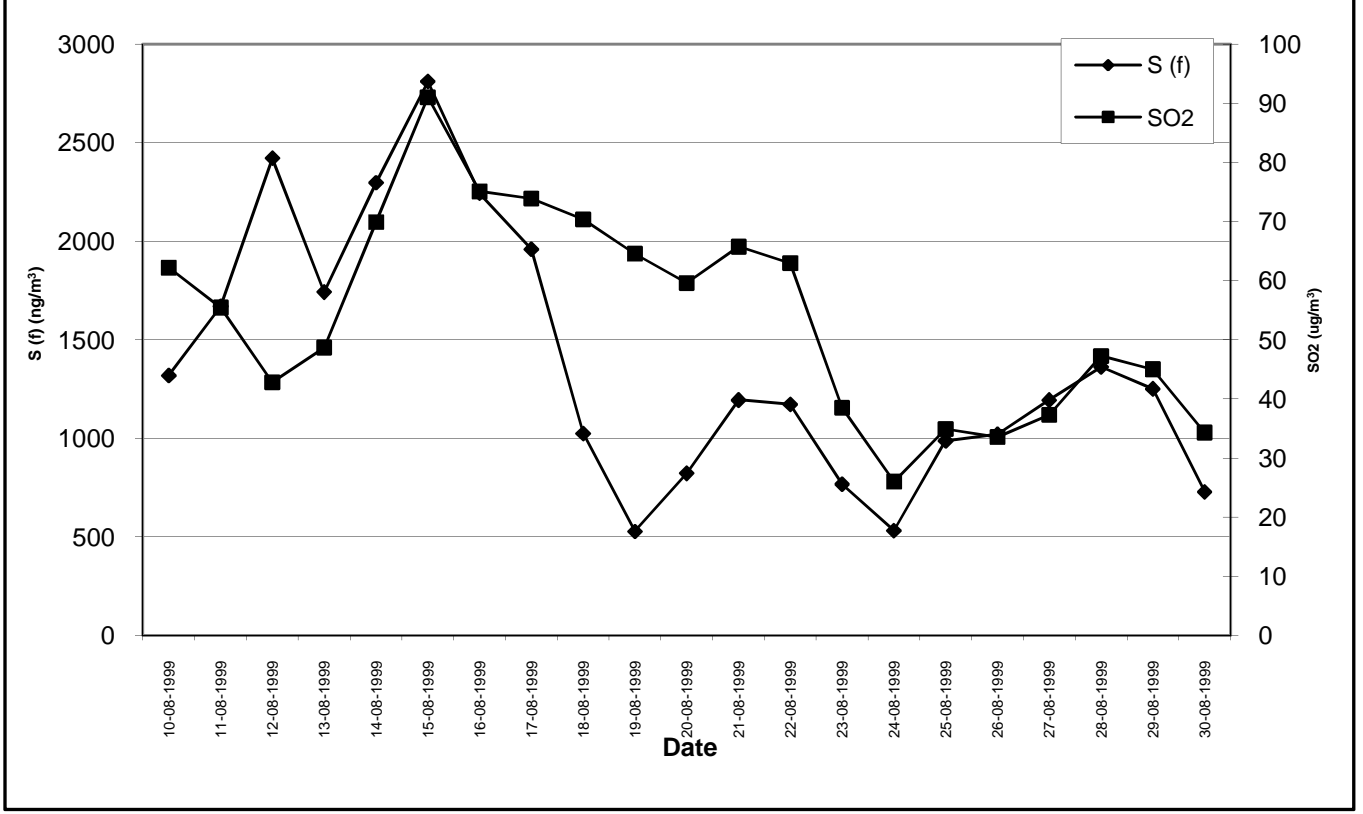

Fig. 2: Time series of $\mathrm{S}(f)$ and $\mathrm{SO}_{2}$

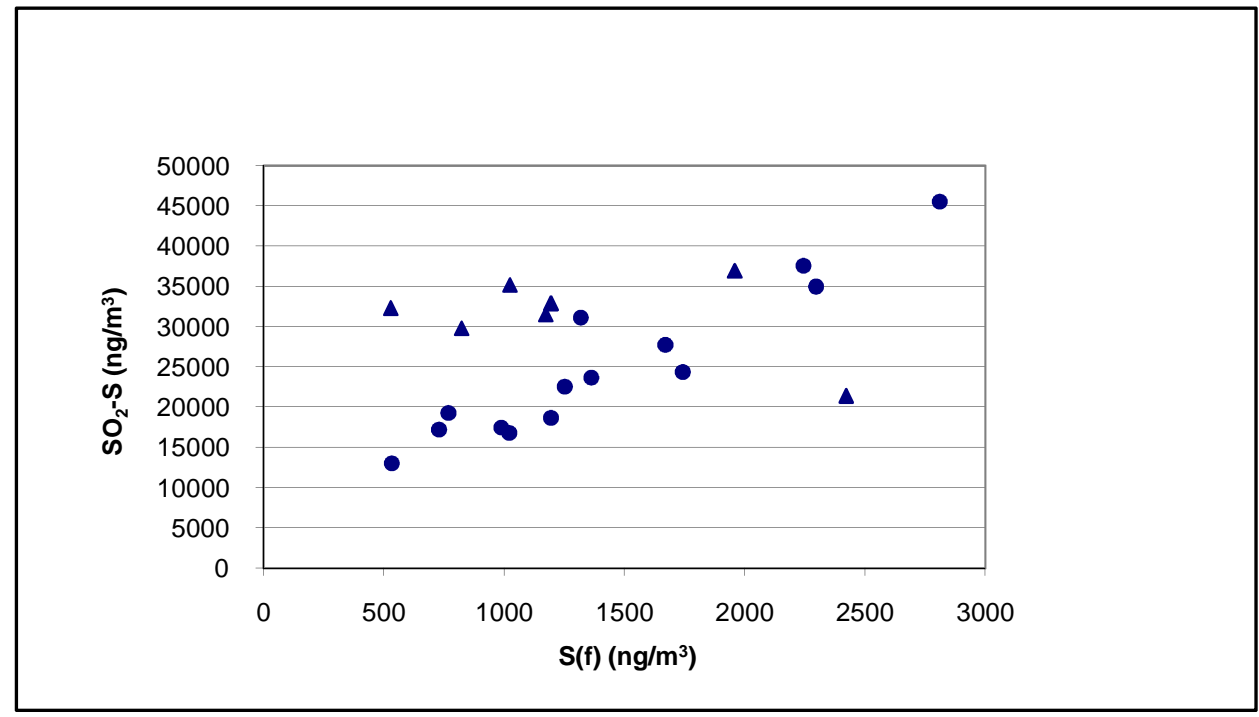

Fig. 3: Regression diagram of $\mathrm{SO}_{2}-\mathrm{S}$ versus $S(f)$ for Gaborone 1999. The regression line refers to the cases of long distance transport (plotted as dots). The equation of the regression line is: $y=13.5 x+5960 \mathrm{ng} / \mathrm{m}^{3}$. The regression coefficient is $R^{2}=$ 0.88 .

\subsection{Variations in levels of trace elements with air mass} trajectories

In order to elucidate the contribution of transboundary pollution to the aerosol of Botswana, 4 days (96 hours) air mass backward trajectories were calculated for the days corresponding to the sampling period as illustrated in Fig. 4 $\mathrm{a}, \mathrm{b}, \mathrm{c}$ and $\mathrm{d}$. The trajectories have been evaluated for two times at 6 a.m. at three heights 50, 150 and 300 meters.
During some days in the measurement period the levels of anthropogenic fine particle elements were very high (for example on the $15^{\text {th }}$ and the $25^{\text {th }}$ of August (refer to Figure 1). Thus, when one compares the air mass trajectory diagrams with days of very high concentrations, one notices that the two days correspond to occasions when the air mass trajectory had passed through the Pretoria and Johannesburg region as illustrated in Figures $4 \mathrm{a}$ and $\mathrm{b}$ respectively. It is 
not surprising that anomalies of most of the anthropogenic trace element are correlated to the air masses from South Africa, since Pretoria and Johannesburg are some of the most heavily industrialised cities in Africa. As a comparison

a)

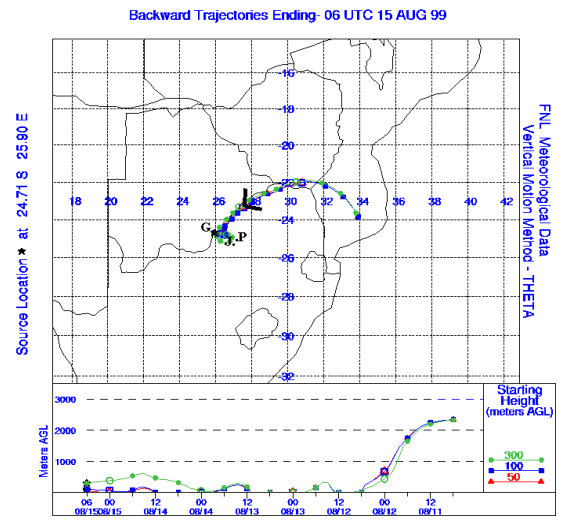

c)

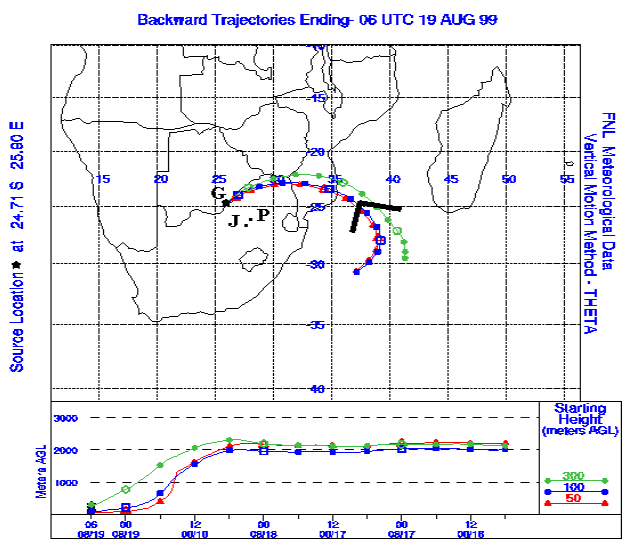

the trajectories of occasions with low levels of $\mathrm{Zn}$ and other anthropogenic elements $\left(19^{\text {th }}\right.$ and $29^{\text {th }}$ August) are shown in Fig $4 \mathrm{c}$ and $\mathrm{d}$. Notice, that in this case the trajectories avoid Johannesburg and Pretoria regions.

b)

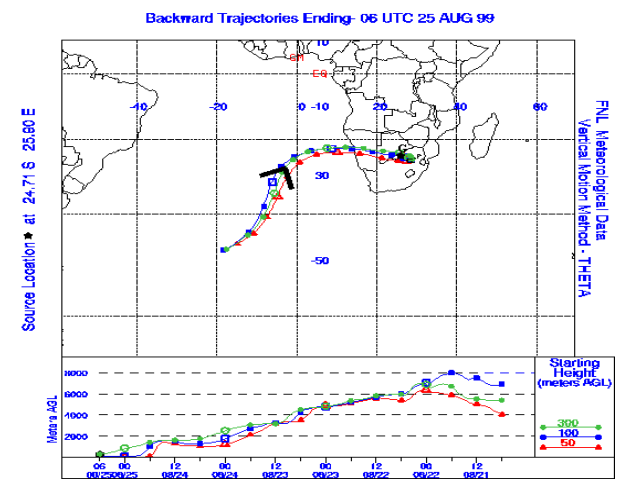

d)

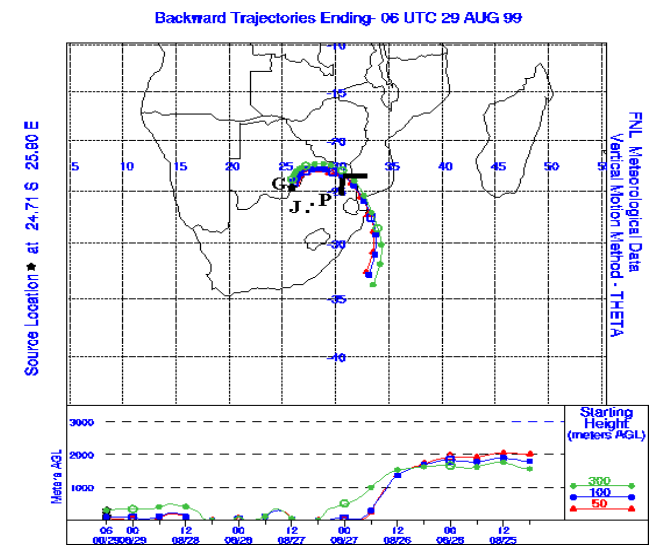

Fig. $4 a, b, c$ and d. Modified 4 days (96 hours) backward air mass trajectories evaluated at three heights 50, 150 and 300 meters for 6 a.m. and 12 noon respectively. The trajectories have been evaluated from the National Oceanic and Atmospheric

Administration (NOAA) air resource laboratory and can be found on its web site (NOAA, 2000). Note, that on the $15^{\text {th }}$ and $25^{\text {th }}$ of August the air mass trajectories reach Gaborone after first Passing the Johannesburg and Pretoria regions. Arrow indicates the direction of movement of the air mass. G-Gaborone, P-Pretoria, J-Johannesburg. 
3.3 Principal Component Analysis

In order to make source apportionment the data matrix was subjected to principal component analysis (PCA) (Statsoft, 1994) with Kaiser normalisation. Tables 1 and 2 shows factor loadings obtained for the fine and coarse fractions treated separately. It can be noted from Tables 1 and 2 that the factors $1 \mathrm{a}$ and $1 \mathrm{~b}$ consists of both natural and anthropogenically derived elements. The likely scenario is that anthropogenic elements have over time been deposited on the soil (Fergusson, 1986) and they become resuspended in the atmosphere with the soil particles. As an example evidence from $\mathrm{Pb}$ studies has shown that surface soil $\mathrm{Pb}$ is predominantly from petrol $\mathrm{Pb}$ in studied areas (Chow, 1970; Gulson et al., 1981).

Factor 2a is likely to be linked to fossil fuel combustion and biomass burning. The elements $\mathrm{K}$ and $\mathrm{Rb}$ are the finger prints of biomass burning (Gaudichet et al., 1995, Moloi et al., 2000).

Factor $2 \mathrm{~b}$, is likely to be traffic emissions and biomass burning. Traffic emits both $\mathrm{Br}, \mathrm{Pb}, \mathrm{BC}$ and $\mathrm{SO}_{2} . \mathrm{Pb}$ and $\mathrm{Br}$ are finger print of traffic leaded gasoline (Harrison and Sturges, 1983; Liu et al., 1995). Fossil fuel combustion emits both $\mathrm{BC}$ and $\mathrm{SO}_{2}$.

Table.1: Factor loadings from principal component

\begin{tabular}{lll|}
\multicolumn{3}{c}{ analysis $(P C A)$ for the fine elements. } \\
\hline $\begin{array}{l}\text { Fine } \\
\text { elements }\end{array}$ & Factor 1a & Factor $2 \mathrm{a}$ \\
\hline $\mathrm{Si}$ & .659 & .512 \\
$\mathrm{~K}$ & .534 & .789 \\
$\mathrm{~S}$ & & .748 \\
$\mathrm{Ca}$ & .896 & \\
$\mathrm{Ti}$ & .887 & .417 \\
$\mathrm{Cr}$ & .752 & .406 \\
$\mathrm{Mn}$ & .821 & \\
$\mathrm{Fe}$ & .903 & \\
$\mathrm{Ni}$ & .789 & .409 \\
$\mathrm{Cu}$ & .906 & \\
$\mathrm{Zn}$ & .816 & \\
$\mathrm{Br}$ & .941 & \\
$\mathrm{Rb}$ & .808 & .498 \\
$\mathrm{~Pb}$ & .952 & \\
$\mathrm{SO}$ & .482 & .478 \\
$\mathrm{BC}$ & .783 & \\
\hline
\end{tabular}

Table.2: Factor loadings from principal component

\begin{tabular}{llc}
\multicolumn{3}{c}{ analysis $(P C A)$ for the coarse elements. } \\
\hline Coarse & Factor $1 \mathrm{~b}$ & Factor $2 \mathrm{~b}$ \\
Elements & & \\
\hline $\mathrm{Si}$ & .949 & \\
$\mathrm{~K}$ & .942 & \\
$\mathrm{Ca}$ & .974 & \\
$\mathrm{Ti}$ & .961 & \\
$\mathrm{Cr}$ & .607 & \\
$\mathrm{Mn}$ & .934 & \\
$\mathrm{Fe}$ & .964 & \\
$\mathrm{Ni}$ & .773 & \\
$\mathrm{Cu}$ & .862 & \\
$\mathrm{Zn}$ & .909 & \\
$\mathrm{Br}$ & .709 & .556 \\
$\mathrm{Rb}$ & .937 & \\
$\mathrm{Sr}$ & .912 & .796 \\
$\mathrm{~Pb}$ & .817 & .584 \\
$\mathrm{SO}$ & & \\
$\mathrm{BC}$ & .629 & \\
\hline
\end{tabular}

\section{CONCLUSION}

The diurnal variation of elements fluctuates a lot which could be a sign of locally generated pollution as well as transboundary pollution.

Transboundary pollution from South Africa is noticeable. Elevated concentrations of elements correspond to the situation when the air mass went through the regions around Pretoria and Johannesburg in South Africa.

Principal component and regression analysis has pointed to a few sources, which contribute to the Gaborone aerosol. The results indicate relatively high levels of local air pollution originating from both the natural and anthropogenic sources. As an example it can be mentioned that $\mathrm{Pb}$ and $\mathrm{Br}$ show a very high correlation coefficient indicating that they come from the same source which in this case is traffic. Meanwhile the results of principal component analysis have shown that the Gaborone aerosol is heavily influenced by several sources including biomass burning.

It is desirable that measurements with longer sampling times be undertaken in the future in order to further elucidate some of the observed phenomena. Longer time sampling measurements will give results with more statistical significance, which can help in giving a better resolution of factors when principal component analysis is applied. 


\section{REFERENCES}

[1] Air Pollution Control. 1995. Annual report. Department of Mines, Printed by the Government Printer, Gaborone, Botswana.

[2] Butcher, S.S., Charlson, R.J., Orians, G.H., Wolfe, G.V. 1992. Global Biogeochemical cycles, pp.226. Academic Press, London.

[3] Chow, T.J., 1970. Lead accumulation in roadside soil and grass. Nature 225, 295-296.

[4] Chimidza, S., Moloi, K., 2000. Identification of sources of aerosol particles in three locations in eastern Botswana, Journal of Geophysical research 105(D14), 17811-17818.

[5] Clarke, A.G., Azadi-Boogar, G.A., Andrews, G.E., 1999. Particle size and chemical composition of urban aerosols. The Science of the Total Environment 235, $15-24$,

[6] Gaudichet, A., Echalar, F. E., Chatenet, B., Quisefit, J. P., Malingre, G., Cachier, H., Buat-Menard, P., Artaxo, P., Maenhaut, W., 1995. Trace Elements in Tropical African Savanna Biomass Burning Aerosols. Journal of Atmospheric Chemistry 22, 19-39.

[7] Gulson, B.L., Tiller K.G., Mizon K.J., Merry R.H., 1981. Use of lead isotopes in soils to identify the source of lead contamination near Adelaide, South Australia. Environmental Science Technology 15. 691696.

[8] Fergusson, J.E., 1986. Lead: Petrol lead in the environment and its contribution to human blood lead levels. The Science of the Total Environment 50, 1-54.

[9] Harrison, R.M., Sturges, W.T., 1983. The measurement and interpretation of $\mathrm{Br} / \mathrm{Pb}$ ratios in airborne particles. Atmospheric environment 17(2), 311-328.

[10]Liu, X., Hopke, P.K., Cohen, D., Bailey, G., 1995. Sources of fine particle lead, bromine, and elemental carbon in south-eastern Australia. The Science of the Total Environment 175, 65-79.

[11] National atmospheric emissions inventory http://naei.defra.gov.uk/overview/issues?issue_id=2

[12] National oceanic and atmospheric administration NOAA., 2000. http:/www.arl.noaa.gov/ready.html

[13] National Science Foundation NSF., 1999. Office of Legislative and Public affairs, http://www.nsf.gov/od/lpa/news/press/99/pr9940.htm.

[14] Seinfeld, J. H., 1986. Aqueous-Phase Atmospheric Chemistry, in Atmospheric Chemistry and Physics of Air Pollution, pp196-198, John Wiley \& Sons, New York.
[15] Selin, E., Oblad M., Standzenieks, P., Boman, J., 1991. Polarization effects in a $\mathrm{Si}(\mathrm{Li})$ Detector, X-ray Spectrometry 20, 325-330.

[16] Selin, L.E., Moloi, K., Stikans, M., Chimidza, S., 1998. Levels and Sources of Particle Air Pollution in Botswana studied by EDXRF Technique. in Proceedings of the European Conference on Energy Dispersive X-Ray Spectrometry 1998, pp. 269-273, Bononia University Press, Bologna.

[17] StatSoft., 1994. Factor Analysis, in Statistica for Windows (Volume III): Statistics, pp. 3185, StatSoft Inc., Tulsa, USA.

[18] Standzenieks, P., Selin, E., 1979. Background Reduction of X-ray Fluorescence Spectra in a Secondary Target Energy Dispersive Spectrometer, Nuclear Instruments and Methods 165, 63-65.

[19] Thermo Environmental Instruments Inc., 1996. Model 43S Trace level Pulsed Fluorescence $\mathrm{SO}_{2}$ Analyser Instruction Manual.

[20] Yu, T., Chang, L.W., 2000. Selection of the scenarios of Ozone pollution at the Southern Taiwan area utilizing principal component analysis. Atmospheric environment 34, 4499-4509.

[21]Zunckel M., Piketh S. and Freiman T., 1999. Dry deposition of sulphur at a high altitude Background station in South Africa, Water, Air and Soil Pollution $115,445-463$. 